\title{
OB 70-LETNICI POUČEVANJA IN RAZISKOVANJA GEOGRAFIJE NA LJUBLJANSKI UNIVERZI
}

\author{
Dusan Plut*
}

IZVLEČEK

UDK 91(497.12)"1919-1989"

Oddelek za geografijo je na ljubljanski univerzi od njene ustanovitve. Predstavlja slovensko matix̌no geografsko ustanovo, ki opravlja pedagoß̌ko in znanstveno-raziskovalno vlogo. $\mathrm{V}$ bodoce bo ena izmed osrednjih nalog uskladiti specializacijo in geografsko sintezo.

ABSTRACT

UDC 91(497.12)"1919-19S9"

SEVENTY YEARS OF GEOGRAPHICAL TEACHING AND RESEARCH AT THE UNIVERSITY OF LJUBLJANA

The Department of Geography is a part of the University of Ljubijana since established in 1919. The Department is the Slovenian main gcographical institution educating students and working within different studies and research programmes. In the future the synthesis of the geographical work donc and outleveling of the special geography branches might be main goals to reach.

Izčrpavajođ tempo sodobnega življenja in silovit razmah vedenja o svetu pogosto ne dopušca umirjenega zazrtja $v$ preteklost, $v$ pionirska semena posameznih nacionalnih ved. Zgolj okrogle obletnice so na srečo le š negovani nuejniki, priložnost za postanek, razmislek, prilika za navdih ustvarjalnih zamisli, tudi z izkuß̌njami preteklosti. Prihodnost prouđevanja in raziskovanja slovenske geografije je morda njena sicer krcpko preoblikovana preteklost. Poskusil bom v skopo odmerjenih vrsticah podati osebno in zato nepopolno videnje razvoja Oddelka za geografijo ljubljanske univerze kot vzpodbudo nenehnega iskanja morda že drugace prehojenih poti nałe prihodnosti.

V mozaiku slovenskih geografskih inštitucij in geografov sedanjosti si težko predstavljamo pionirske, predvsem kadrovske težave geografije na novo ustanovljeni ljubljanski univerzi 1. 1919. Čeprav sta bili za geografijo predvideni kar dve stolici (fizixna geografija, antropogeografija), je bil redni profesor za geografijo imenovan sele aprila 1920 in sicer dalmatinski Hrvat dr. Artur Gavazzi, dotlej redni profesor na zagrebški univerzi (Ilešic, 1969). Bistveno je, da je v institutu zbral okrog sebe skupino zagretih Studentov in diplomantov. Le-ti (kot Valter Bohinec, Roman Savnik, Franjo Bas, Ivo Rubic in drugi) so se kljub skromnim delovnim pogojem mladostno zagnano lotili strokovnega dela in tudi ustanoviii Geografsko drustvo Slovenije (1922). Celo vec - ob pomanjkanju literature in denarja se je petorica zagnancev obvezala, da se

\footnotetext{
*dr., univ. doc. ,Oddelek za geografijo, Filozofska fakulteta, 61000 Ljubljana, Aškerčeva 12
} YU. 
vsak od njih naroxi na Glasnik Geografskega društva v Beogradu in vsak §e na eno inozemsko geografsko revijo (Bohinec - Savnik, 1927). Zavidanja vredna stanovska zavest, ki bi bila tudi danes še kako zažcljena!

Študij geografije je $v$ prvem obdobju potekal $v$ glavnem po vzorcu avstrijskega studijskega sistema. Po prvi reformi studija geografije 1.1925 pa se je najveð studentov odloxilo za tradicionalno povczavo studija geografije in zgodovinc, ki je na slovenski univerzi ostala v ospredju vse do danes. Po odhodu prof. Gavazzija na novo ustanovljeno katedro za fizieno geografijo v Zagrebu, je bil 1.1927 na njegovo mesto izvoljen dr. Anton Melik, ki je nato skupaj z dr. Svetozarjem Ilesicem (od leta 1933) prakticno vse do konca 60 -ih let kreiral studij in znanstveno usmerjenost slovenske univerzc. Oba sta se $\mathrm{z}$ veliko vnemo lotila pedagołkega in znanstveno raziskovalnega dela, poraslo je tudi stevilo studentov z geografijo kot glavnim predmetom $(10-20 \mathrm{v}$ vseh letnikih skupaj). Osnovan je bil zelo živahen in razgiban seminar, uvedene intenzivne terenske vaje, organizirane ( $\mathrm{z}$ majhnimi izjemami) tako za ucno osebje kot za Studente na lastne stroške. Ob živahnima in podjetnima geografoma je slovenska gcografska znanost suvereno in plodno stopila $v$ jugoslovansko, evropsko in svetovno znanstveno areno, Geografski vestnik pa se je razvil v ugledno znanstveno revijo. $V$ znanstveno raziskovalnem pogledu je bil poudarek na gcomorfoloskem, prebivaistvenem in agrarnogeografskem proucevanju historixno-genetske oziroma fiziognomsko-morfoloske smeri (Ilešix, 1969). V geografskem proučevanju Slovenije je bilo v prvih tridesetih letih glede na pogoje dela torej veliko storjenega, obenem pa so seveda ostale se velike vrzeli in neenakomernosti tako giede posameznil panog geografije (hidrogeografije, biogeografije, ekonomske georafije), kot tudi glede obravnave slovenskih pokrajin (IleSic, 1978, s. 215). Osrednji povdarek pa je bil pod vplivom prof. dr. Melika na geomorfologiji, prouxevanju naselij in agrarni geografiji.

Šele po 2. svetovni vojni je slovenska geografija kot ena najmlajßih nacionalnil ved pridobila Sirక̌e možnosti za organizacijski, studijski in vsebinski razmah, vendar je vse do prixetka 60 -ih let organizacijski okvir za geografijo na univerzi ostai dokaj skromen. Oba profesorja (Melik, Ilešic) sta se nekaj let sama ubadala z obsežnim pedagoSkim dclom (organiziran je bil enopredmeten studij), izdajo ucbenikov, znanstveno-raziskovalnim delom in stevilnimi pomembnimi nestrokovnimi funkcijami. Potrcbe so se stopnjevale tudi $\mathrm{z}$ narašajocim stevilom studentov ( $30-60 \mathrm{v}$ vseh Ietnikih) in uvajanjem novih predmetov. Razmere so se nekako olajšale šcle po 1. 1959, ko je tretje predavateljsko mesto zasedel dr. Vladimir Klemencix, odobrenih in zasedenih pa je bilo tudi vec asistentskih mest. V povojnem obdobju do 1.1960 je vsako leto diplomiralo vsaj 10 geografov, 12 geografov pa je doktoriralo. Vexje stevilo doktorantov iz drugih republik kaže na ugled geografije na ljubljanski univerzi.

Po ustanovitvi Geografskega inštituta Univerze (z zemljepisnim muzejem) je znanstveno raziskovalno delo sodelavcev oddelka dobilo solidne organizacijske in finan- 
cne temelje, opravljena pa je bila tudi smiselna razdelitev delovnih podroxij s takratnim Institutom za geografijo SAZU in Institutom za raziskovanje krasa v Postojni. V sestdesetih letih se je trem dosedanjim ux̌nim mocem pridružilo več novih fakultetnih uxiteljev (dr. Igor Vrišer, dr. Marjan Žagar, dr. Darko Radinja, dr. Vladimir Leban, dr. Jakob Medved, dr. Ivan Gams, dr. Mirko Pak). Tako se je maticna geografska cnota kadrovsko moæno okrepila. L.1961 je bil Geografski institut pri Univerzi preimenovan v Oddelke za geografijo, I. 1975 pa v Pedagosko - znanstveno enoto za geografijo pri Filozofski fakulteti (Vriß̌er, T.Šifrer, 1978). Dvopredmetni in dvostopenjski Studij je omogocal polno zaposiitev nasim diplomantom na osnovnih in srednjih కolah, obenem pa se je zacela krepiti zaposlitev izven §ole. Kratkemu obdobju treh కolskih usmeritev na drugi stopnji (pedagoska, regionalno planiranje in geografija turizma) je sledila pretvorba usmeritvenih $v$ obvezne predmete za vse studente. $\mathrm{V}$ drugi polovici 60 -ih let se je Stevilo studentov za 1 . in 2. letnik ustalilo na stevilu, ki velja se danes in sicer:

1. letnik - 100 studentov (pod A in B)

2. letnik - 25 do 30 studentov.

Zaradi stopenjskega Studija pa je bilo $\mathrm{v}$ tretjem in cetrtem letniku manj studentov $(10-20)$ kot danes $(30-40)$. V letu 1966 se je priðel tudi podiplonski studij, ki se je kasneje కe razmahnil, danes pa postaja vse bolj logixna oblika izpopoln jevanja najbolj nadar jenih diplomantov.

TABELA 1: Število diplomantov na Oddelku za geografijo FF (geografija pod A):

$\begin{array}{lc}\text { Obdobje } & \text { Število } \\ \text { do } 1.1940 & 55 \\ 1941-1960 & 197 \\ 1961-1989 & 400 \\ \text { Skupaj } & 652\end{array}$

V 70 letnem obdobju je torej visokosolsko izobrazbo z geografijo pod A pridobilo 652 studentov. K temu je potrebno pristeti కe okoli 200 diplomantov, ki so geografijo Studirali kot B predmet. Doktorat znanosti je pridobilo 59 kandidatov, magisterij pa 27 sluSateljev. V 80-ih letih je diplomiralo povprěno 10 - 15 studentov (1980 - 1988 skupaj 135). Ob koncu solskega leta $1988 / 89$ je stel Oddelek za geggrafijo 25 zaposlenih in sicer:

redni univerzitetni profesorji (6): dr.Ivan Gams, dr. Vladimir Klemencix̌, dr. Máatjaž Jersice, dr. Mirko Pak, dr. Darko Radinja, dr. Igor Vrišer; izredni univerżitetni profesorji (2): dr. Jurij Kunaver, dr. Franc Lovrencak; univerzitetni docenti (2): dr. Marijan Klemencič dr. Dušan Plut; univerzitetni asistenti (4): dr. Andre Černe, dr.Anton Gosar, mag. Marjan Bat, Maja 
Umek;

mladi raziskovalci (2): mag. Terezija Kirbus (v pretoku), Darko Ogrin (za obnovo); nepedagoški sodelavci (9): Tonð̌ka Abbad, Mojca Dolgan-Petrix, Ida Knez, Pavel Markelj, Irena Petroßa, Tatjana Pretnat, Tatjana Sifrer, Janja Turk, Ciril Vojvoda.

Po mnenju S.Ilesica $(1969$, s. 241) si je ljubljanska geografska sola s svojim osr $x$ jem na Univerzi v 60 -ih letih pridobila nadpovprecen ugled in neke vrste vodilno vlogo v jugoslovanski geografiji, stopnjevala pa se je tudi živahna mednarodna dejavnost. Široko razvejana znanstveno-raziskovalna dejavnost clanov Oddelka je zaradi hitre preobrazbe slovenskih pokrajin in povcčane specializacije raziskovanja segla na nova podrox ja: geografijo krasa, funkcijsko zasnovano klimatogeografija in hidrogeografijo, biogeografijo, prouとevanje naravnih nezgod, prouðevanje intenzivnih sprememb podežclja in mest zaradi deagrarizacije, urbanizacije, industrializacije in razvoja turi$\mathrm{zma}$, opredelitev in proucevanje narodnostno mesanih podrocij itd.

V povojnem obdobju so se na Oddelku postopoma izoblikovala raziskovalna geografska podroxja, ki so dala pečat tudi celotni usmeritvi slovenske geografije. Naj omenim zlasti:

- historix̌ne in regionalno geografske študije (dr.A.Melik, dr. S. Ilešǐ, dr.J.Medved, dr. V. Leban);

- agrarna geografija (dr. S.liešix, dr. A.Mclik, dr. J. Medved, dr. V. Klemenčix);

- geografija turizma (dr. M. Žagar, dr. M. Jersic, cir. A. Gosar);

- geografija krasa (dir. I. Gams, dr. D. Radinja, dr. J. Kunaver);

- regionalno planiranje (dr.I.Vrišer, dr. A. Černe);

- narodnostna problematika (dr.V. Klemencix, dr. M. Klemencix);

- varstvo okolja z biogeografijo (dr. D. Radinja, dr. I. Gams, dr. F. Lovrenđak, dr. D. Plut);

- urbana geografija (dr. M. Pak, dr. I. Vriß̌er).

Znanstveno-raziskovalna in pedagoska dejavnost Geografskega oddeika na FF se je sprva razmahnila $z$ ustanovitvijo Inštituta za geografijo Univerze, konkretne oblikc sodelovanja pa so se razširilc tudi z že obstojčima geografskima inštitucijama ter z ustanovljenima geografskima oddeikoma v okviru ljubljanske in mariborske pedagoske akademije (Ilešǐ, 1978; Vrišer, T.Šifrer, 1978).

Trem osnovnim katedram (regionalna geografija, fiziěna geografija in družbena geografija) so se pridružile క̌e katedre za regionaino planiranje, turizem, varstvo okolja ter za didaktiko geografije. $\vee$ pedagoški proces pa so se vkljucevali tudi predavatelji sorodnih ved. 
Pri Siroki pahljaxi pedagoškega dela je potrebno omeniti tudi bogato izmenjavo predavateljev in studentskih ekskurzij iz tujih univerz, na oddelku so pogosti domaci in tuji mladi raziskovalci in že renomirani proǔevalci Jugoslavije, clani našga Oddelka pa so pogosti gosti na jugoslovanskih in tujih univerzah, na kongresih in posvetovanjih doma in po svetu. S stažisti-raziskovalci si Oddelek zagotavlja načrtnejšo kadrovsko politiko in krcpi povezovanje s prakso, ki se odraža tudi z vodenjem ali sodelovanjem clanov Oddelka $v$ Stevilnih raziskovalnih projcktih nacionalnega in meddržavnega nivoja (npr.: človek in biosfera, antropogeno preoblikovanje krasa, geomorfoloska karta Jugoslavije, narodne manjšne in odprta meja, naravni viri, policentrixni regionalni razvoj).

Postopoma se je izoblikovaia osrednja geografska knjižnica z vex kot 30.000 knjižnimi enotami, bogata kartografska zbirka (z okoli 35.000 zemljevidov), postopoma se dodatno opremlja fizixnogeografski laboratorij, $v$ pedagoß̌ko znanstevi proces se uvaja delo z računalniki.

Širsa družbena kriza in obencm nekateri pereči problemi geografskega క̌tudija in raziskovanja pa nas tudi ob jubileju silijo k trezni in kritieni analizi stanja kot osnove $\mathrm{k}$ iskanju uspešnejših poti slovenske geografije in samega Oddelka. Nanizajmo le nekatere osrednje dileme. Brez dvoma je zmanjševanje našega kadra v osnovnih in sred$\mathrm{njih}$ \olah kot posledica krčenja pouka geografije izredno perex problem, kljub istoCasnemu porastu geografov na delovnih mestih izven కol (Gams, 1983). Žal nimamo podrobne empiricne analize vzrokov za tako stanje, ki pa jih moramo verjetno iskati tudi $v$ naxinu geografske vzgoje in izobraževanja, morda celo $v$ podzavestnem podcenjevanju "Solske" geografije. Ali je navedeno de jstvo tudi odraz predmetne razdrobljenosti, premajhne popularizacije geografskih raziskovanj, pomanjkanja naxrtnega skupinskega raziskovanja ? Sodim, da je potrebna nacrtnejła pedagosko- raziskovalna strategija Oddelka, ki bo znala ravnovesno uskladiti neobhodnost specializacije in potrebnost geografske splošnosti in kompleksnosti. To verjetno v vzgojno - izobraževalnem polju pomeni na eni strani logicno organsko združevanje geografskih predmetov dvopredmetnega pedagoškega studija in pretehtano uvajanje enopredmetne nepedagoß̌ke geografije ter okrepitev podiplomskega studija. Obenem nas praksa in agresivnost mejnih ved dobesedno prisiljuje v skupinsko delo, kot je žc potckajoča izdelava prepotrebne geografske monografije Slovenije in Atlasa Slovenije, ki iz različnih vzrokov š vedno ni ugledal svetlobe. Zaradi oraganizacijskih razdrobljenosti geografije so redke medinstitucijske skupne raziskave, projektne povezave, združevanje naporov za smotrno zasnovano, medsebojno usklajcno raziskovalno opremljenost in medsebojno racunalniško povezan slovenski geografski informacijski sistem. Vrsto nalog bi lahko uspešno dosegli kljub obstojeci inštitutski razdeljenosti in pogosto prisotni ekstenzivnosti raziskovanja. 
Zaskrbljujoce je dejstvo, da je po smrti prof. Ilesixa bistveno upadlo zanimanje in delo na podroxju regionalno geografske metodologije in teorije geografije. Ilustrativno je dejstvo, da v sicer sila razvejanem ux̌nem nacrtu našega Oddelka ni sintetix̌nega teoretixnega predmeta. Tako tudi tu velja ugotovitev Vrišrja (1983) o zaostajanju celotne jugoslovanske geografije glede novih konceptov $\mathbf{k}$ reintegraciji geografije in prenosu sodobnega regionalno geografskega koncepta $\mathbf{v}$ vse geografske sfere. Kljub nekaterim uspešnim prodorom nam se ni uspelo konceptualno in metodolosko optimalno združiti vse tri geografske komponente (fizǐ̌no, socialno in regionalno) $v$ zadovoljivo celoto in celotno geografijo predstaviti kot ekspertno vedo o prostoru, pokrajini, okolju, regiji. Gre seveda za doigotrajen proces, dolocen optimizem pa vzbujajo npr. povezovalno zasnovane magistrske in doktorske teme ter pospeseno uvajanje sodobnih računalniskih tehnik.

Silovitost procesov $\mathrm{v}$ pokrajinski preobrazbi Slovenije, Jugoslavije in celega sveta, bolexe prepoznavanje gcografsko pogojenih razvojnih omejitev (prostor, naravni viri, samoxistilne zmogljivosti) prinaša nove izzive $v$ studij in raziskovalno delo naßega Oddelka in cclotne geografije. Geografska praksa je sicer zavrnila nekatera najbolj ¿rnogleda, seveda dobronamerna razmišljanja prof. Ilešč o blodenju po poteh razkrajajocega dualizma ali pluralizma v slovenski geografiji (Hešx, 1982). Novi metodoloß̌ko - teoretski Łtudijski aplikativni in celo civilizacijsko - eksistenen izzivi pa potrjuje jo neobhodnost ve ${ }^{X} j e$ inovativne odzivnosti in dosežkov slovenske geografije.

Ob razxlenjanju zclo aktualnega odnosa med geografijo in varstvom okolja Radinja (1987) upravixeno poudarja, da v Sloveniji ne pogresamo le kompleksne, regionalne, problemske ali kakršne druge geografije in $\mathrm{z}$ njo povezanega skupnega dela. Pogresamo tudi pogiobljeno, celovito in kritixno oceno našega dela, tako navzven kot navznoter.

Posametna razmišljanja o pomanjkljivosti slovenske geografije so se v večji meri pojavila v začetku 70 -ih let, vendar celovitcjši pretres usmer jenosti slovenske geografije ni bil opravljen (Plut, 1982). Želim, da bi zato ob 70. letnici Oddelka za geografijo na Filozofski fakulteti kritixno in dobronamerno spregovorili tako o uspehih kot tudi o kritixnih tockah v Studiju in znanstveno - raziskovalnem delu. 


\section{LITERATURA}

Bohinec V., Savnik R., 1972. Kako je nastalo geografsko društvo Slovenije. Geografski vestnik XLIV, Ljubljana. s. 161 - 165.

Gams I., 1983. Stanje in perspektive slovenske raziskovalne geografije. Geografski vestni $L V$, Ljubljana. s. 9 - 18.

Klemencið V., 1989. Oddelke za gcografijo. Zbornik Filozofske fakultete v Ljubljani 1919 - 1989, Ljubl jana. s. 113 - 117.

Ileši S., 1978. Petdesct letnikov Geografskega vestnika. Geografski vestnik L, Ljubljana. s. 163 - 174.

IleŠič S., 1969. Geografija. Petdeset let slovenske univerze v Ljubljani, Ljubljana. s. $231-242$.

Ilesiǐ S., 1972. Slovenska geografija v petdesetih letih Slovenskega geografskega druStva. Geografski vestnik XLIV, Ljubljana. s.165 - 180.

Ilesic S., 1950. Slovenska geografija v 30 letih ljubljanske univerze. Geografski vestnik XXII, L jubljana. s.215 - 218 .

Plut D., 1982. Geografija - med Scilo in Karibdo. Geografski obzornik 3 - 4, Ljubljana. s. 31 - 42.

Razprave o geografiji, 19S1. Geografski vestnik LIII, Ljubljana. s. 85 - 92.

Radinja D., 1987. Varstvo okolja in geografija . Zbornik 14. zborovanja slovenskih geografov, Postojna. s. $19-22$.

Vrišer I., 1987. Razvojne dileme suvremene jugoslovanske geografije. Geografski glasnik XLIX, Zagreb. s. 13-16.

Vrišer I., Šifrer T., 1978. Geografska veda v Sloveniji.

Geographica Iugoslavica I, Ljubijana. s. 49 - 58 . 


\section{ZUM ANLASS DES SIEBZIGJÄHRIGEN BESTEHENS DER GEOGRAPHIE- FORSCHUNG UND DES GEOGRAPHIE-UNTERRICHTS AN DER UNIVER- SITÄT VON LJUBLJANA}

Dic ersten Schritte der jungen Universităt von Ljubljana waren im Jahre 1919 zwar zaghaft, jedoch fest entschlossen den Geographicunterricht an der Universităt zu gestalten. Artur Gavazzi, cin anerkannter Professor aus Zagreb, wurde nach Ljubljana berufen. Um ihn versammelte sich eine Gruppe eifriger Studenten die trotz schlechten Bedingungen fleissig zu arbeiten begannen.

Den năchsten Höhepunkt erreichte die slowenische Gcographie als Anton Melik zum Geographieprofessor im Jahrc 1927 crnannt wurde. Die crsten Versuche eine Heimatkunde zu gestalten wurden unter seiner Leitung cingeleitet. Seit 1933 wurde Professor Svetozar Ilešx an den zweiten Geographiclehistuhl berufen worden. Nach eigenen Angaben wurden intensive Forschungsvorhaben im Rahmen der Geomorphologie, der Siedlungsgeographie und der Agrargeographie in den dreissigen Jahren unternommen.

Erst nach dem II. Weltkrieg bckam die Geographie, damals schon ais Nationalwissenschaft anerkannt, auch entsprechende Raum und Arbeitsbedingungen. Besonders nach 1959 als Professor Vladimir Klemencix als critter Lehrstuhlinhaber berufen wurde. In diese Zeit fälit auch das Gründen des Geographischen Institutes der Universität, womit auch den Lehrstuhlinhabern solide Möglichkeiten für Forschung und Lehre gegeben wurden.Nach der Meinung von Professor Ilełix konnte die slowenische Geographic damals als die fortschrittlichste Jugoslawiens angesehen werden. Breit gefächerte intcrnationale Vcrbindungen wurden gegründet, Studien cinzclner Prozesse und Gegenden wurden theoretisch und methodologisch fest untermauert, die Zahl der Diplomstucienten übertraf die Zahl 120.

Den drei Grundlehrstühlen für die physische, regionale und Humangeographie folgten die Lehrstühle für die Regionalplanung, den Tourismus, die Umweit und die Geographiedidaktik. Letzlich wird auch den erwähnten Themen mehr Forschungsineteresse gewidmet: der Mensch und seine Unwelt werden studiert, die antropogenen Karstformen besprochen und die nationale Minderheiten und Grenzen erläutcrt.Es wurden Stuäien über Naturresourcen und die polizentrische Regionalentwicklung gefertigt.

Die zukünftige Geographieforschung und -Lehre an der Abteilung für Geographie der Universität von Ljubljana mochte extenzielle Fragen des menschlichen Dascins zu crlăutern versuchen und darzustellen. 
DELA - izdane stevilke

1985 Štev.1. Bibliografija v tujini objavljenih del clanov Oddelka za geografijo $1945-1984$, str. 63

No.1. Bibliography of Articles Published Abroad by the Members of the Department of Geography 1945-1984, p. 63

1986 Štev.2. Geografsko prouð̌evanje uvajanja celiðne proizvodnje na Koroß̌kem, str. 98

No.2. Geographical Research on the Inital Stages of the Productive Units in Carinthia, p. 98

1986 Štev.3. O razmer ju med geografijo in etnologijo, str. 160

No.3. About the Relationship between Geography and Etnology, p.160

1987 Štev.4. Teorija in metodologija regionalne geografije, str. 240

No.4. The Theory and Methodology of Regional Geography, p. 240

1987 Štev.5. Socialna geografija in regionalni razvoj, str. 202

No.5. Social Geography and Regional Development, p. 202

1989 Štev.6. Geografija in aktualna vpraŠanja prostorskega razvoja, str. 302

No.6. Geography and Current Questions of Spatial Development, p. 302 